\title{
O USO DA MADEIRA NA MINERAÇÃO E METALURGIA DO OURO DURANTE A ÉPOCA ROMANA EM PORTUGAL
}

\author{
CARLA MARIA BRAZ MARTINS ${ }^{(1)}$
}

Resumo:

\begin{abstract}
A madeira foi uma matéria-prima importante para a exploração mineira e metalurgia no período romano, embora as suas evidências arqueológicas no actual território português sejam escassas, atendendo ao material perecível que é. A mineração consubstanciada na exploração subterrânea apresenta bastantes constrangimentos, particularmente ao nível da segurança, e daí a necessidade de usar escoramentos de madeira em galerias e poços. Este árduo trabalho obriga o mineiro a munir-se de todo um conjunto de instrumentos de ferro encabados por madeira. O evoluir dos trabalhos, por norma através de vários níveis de profundidade, impõe também a necessidade de utilização desta matéria-prima em escadas, assim como em máquinas elevatórias para extracção da água quando se atingem os lençóis freáticos. No tratamento do minério, este material continua também a ser imprescindível, como o descrito por Agrícola para as instalações de separação gravítica. No âmbito do processo metalúrgico, a madeira era a fonte de combustível dos fornos. Não sendo, obviamente, a condição única em todo este processo industrial, a madeira assume-se inequivocamente como uma infra-estrutura (vastas áreas florestadas) importante na exploração mineira "proto-industrial" romana. Deste modo, define-se como objectivo principal deste trabalho caracterizar as diferentes funcionalidades das madeiras provenientes das minas de Mouros (Jales, Vila Pouca de Aguiar), Tresminas (Vila Pouca de Aguiar), Algares (Aljustrel) e S. Domingos, atendendo às duas diferentes fases que estão adstritas à exploração mineira: extracção do minério e sua metalurgia. Os sítios arqueológicos referidos assumem-se como quatro referências na exploração aurífera romana em Portugal, sendo o ouro explorado como minério principal em Jales e Tresminas, e como minério secundário em $\mathrm{S}$. Domingos e Aljustrel, já que a extracção principal recai sobre o cobre.
\end{abstract}

Palavras-chave: madeira, mineração, metalurgia, ouro, romanização

Abstract:

The use of wood in gold mining and metallurgy in Roman time in Portugal

Wood was an important raw material for mining and metallurgy in the Roman period, although its archaeological evidence in the present Portuguese territory is scarce, given the perishable nature of the material. Mining in underground exploration presents a number of constraints, particularly in terms of safety, hence the need for using wood shoring in galleries and wells. This hard work calls for a whole set of iron and wood tools for the miner. The evolution of the work, through various levels in depth, also requires the use of this raw material on stairs, as well as in devices for extraction of the water when groundwater is reached. Wood was also essential for the processing of ore, as described by Agrícola for gravitational separation facilities. In the metallurgical process, wood was the fuel used in furnaces. Not being, of course, the unique condition in this whole industrial process, wood is unequivocally assumed as an important infra structure (large forested areas) in Roman "proto-industrial" mining. In this way, the main objective of this work is to characterize the different functionalities of the wood from the Mouros (Jales, Vila Pouca de Aguiar), Tresminas (Vila Pouca de Aguiar), Algares (Aljustrel) and S. Domingos mines. Two different phases are involved in mining: extraction of the ore and its metallurgy. The mentioned archaeological sites are assumed as four reference sites in the Roman gold exploration in Portugal, gold being exploited as the main ore in Jales and Tresminas, and as a secondary ore in S. Domingos and Aljustrel, where the main extraction was copper.

Keywords: Fuel, Pottery Kiln, Reduction atmosphere, Ethnoarchaeology, Portugal

\section{INTRODUÇÃO}

A madeira no passado foi uma matéria-prima essencial a todo o processo de exploração mineira e consequente metalurgia, independentemente do minério extraído. No entanto, as suas evidências arqueológicas escasseiam em virtude de se tratar de um material perecível, e como tal a sua preservação torna-se difícil em ambientes húmidos e quentes.

Assim, no universo da mineração romana em Portugal, até ao momento, foram apenas detectados vestígios de madeira em Tresminas e Jales, concelho de Vila Pouca de Aguiar, distrito de Vila Real,
S. Domingos, concelho de Mértola, e Algares, concelho de Aljustrel, distrito de Beja (Fig. 1).

Os sítios arqueológicos acima referenciados foram escolhidos pela detecção de madeiras em articulação directa com os trabalhos mineiros romanos, e pela sua importância durante o período romano seja ao nível da dimensão da exploração, seja ao nível das toneladas de minério extraído. Em relação à Mina dos Mouros, Jales e Tresminas o principal minério era o ouro, mas em Aljustrel e S. Domingos este era apenas um minério secundário.

Apesar de abundarem trabalhos sobre a importância destes locais em época romana quanto à

${ }^{(1)}$ Universidade do Minho, Braga (Instituto de Ciências Sociais) / Lab2PT - Laboratório de Paisagem, Património e Território. Email: carlamariabrazmartins@gmail.com 
exploração mineira, já escasseiam os relacionados com os materiais arqueológicos neles encontrados e/ ou exumados designadamente as madeiras.

Neste sentido, os trabalhos de A. Viana, R. Andrade e O. Ferreira - "Minerações romanas de Aljustrel" (1954), focam as madeiras provenientes de Aljustrel, e J. Braga - "Relatório ácerca da mina de cobre, sita na serra de S. Domingos, freguesia de Sant'Anna de Cambas, concelho de Mértola, districto de Beja" (1961), contempla as madeiras provenientes de S. Domingos.
Mais recentemente os trabalhos de C. Domergue englobam também os materiais arqueológicos em associação às minas inventariadas, com particular atenção às minas antigas de Aljustrel - "La mine antique d'Aljustrel (Portugal) et les tables de bronze de Algares" (1983), e "La mina romana de Aljustrel (Portugal) y el patrimonio minero a principios del tercer milénio" (2002), mas também realizando um inventário geral das minas na Península Ibérica "Catalogue des mines et des fonderies antiques de la Péninsule Ibérique" (1987).

\section{Localização das explorações mineiras}

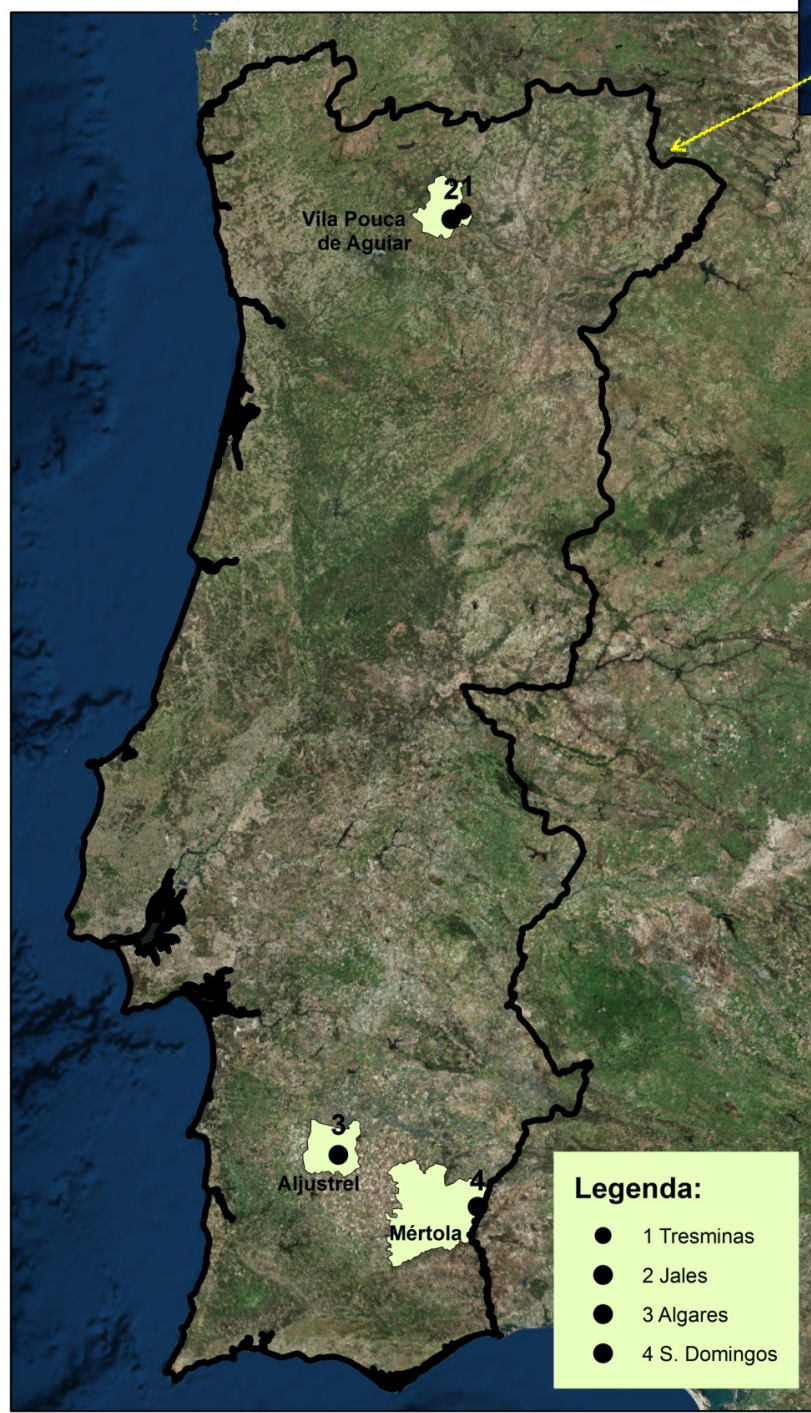

Fontes cartográficas: Atlas do Ambiente Digital, on-line; Bing maps (https://www.bing.com/maps); Google Earth. Fontes bibliográficas: MARTINS 2008.

Fig. 1. Localização das explorações mineiras nas quais foram encontrados elementos em madeira.

Fig. 1. Location of the mining explorations where wood was found.
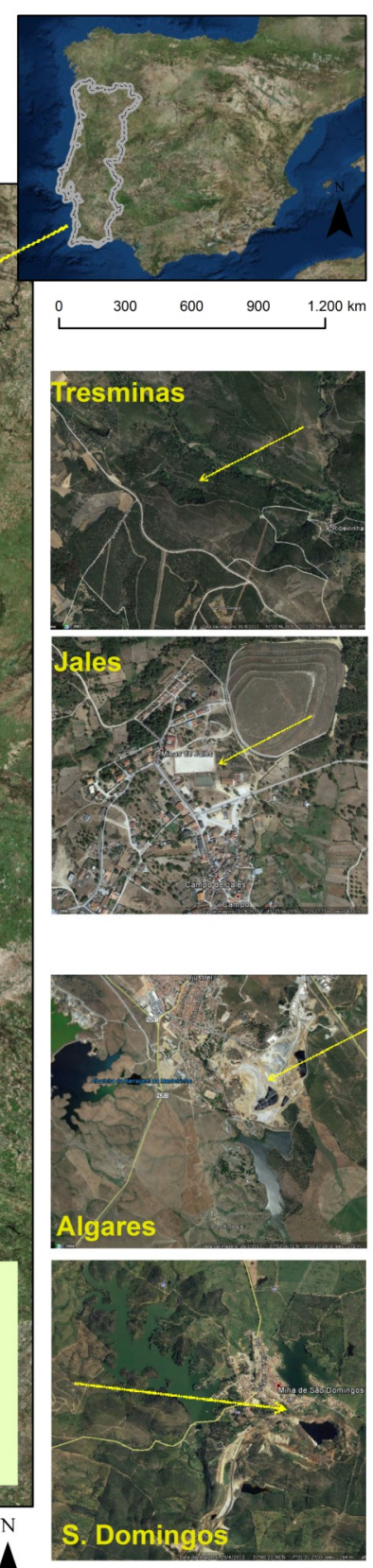
Já em 1997, A. Alarcão coordena uma edição "Portugal Romano. A exploração dos recursos naturais", com uma secção centrada nos metais e na mineração romana no território português, que inclui um inventário da quase totalidade das peças apresentadas neste trabalho, que foram seleccionadas e classificadas por Adília M. Alarcão, Ana Luísa Duarte, António de Carvalho Quintilha, Carlos Fabião, Carlos Marques da Silva, Carlos Tavares da Silva, Fernando Sousa Real, Francisco Alves, João Luís Cardoso, Jorge Raposo, Jürgen Wahl, Miguel Telles Antunes, Regula Wahl-Clerici.

Posteriormente, o trabalho de síntese de C. M. B. Martins "A exploração mineira romana e a metalurgia do ouro em Portugal" (2008) articula do mesmo modo os materiais arqueológicos com as explorações mineiras.

Assim sendo, e tendo em conta os trabalhos e classificações anteriormente realizadas por diversos investigadores, o objectivo deste trabalho não é a identificação do tipo de madeiras, assumindo-se como tal os nomes comuns e não científicos das espécies, mas sim a atribuição de funcionalidades a cada uma das peças estudadas, atendendo à sua tipologia. Importa também perceber o porquê da utilização de certas madeiras na antiguidade e na exploração mineira, pelo que a contraposição com as fontes clássicas, designadamente Plínio e Vitrúvio pareceram ser um contributo relevante. Nesta tarefa foi importante o trabalho de R. Ulrich "Roman woodworking" (2007), que sintetiza o trabalho da madeira e suas diferentes aplicações de acordo com as suas propriedades.

\section{PROVENIÊNCIA E CARACTERIZAÇÃO DAS MADEIRAS ESTUDADAS}

As madeiras estudadas não são provenientes de intervenções arqueológicas, mas sim fruto de prospecções e limpezas levadas a cabo a partir dos anos 30 pelos antigos Serviços do Instituto Geológico e Mineiro, e actualmente depositados em diferentes museus (Tabela 1).

De facto, os materiais alvo deste estudo já foram mencionados e classificados em trabalhos prévios (Viana et al. 1954, Domergue 1983, ALARCÃO 1997), descritos e inventariados (MARTINS 2008), consubstanciando-se as suas dimensões e tipo de madeiras utilizadas na Tabela 2.

Tabela 1. Listagem dos materiais com respectivos locais de depósito.

Table 1. Inventory of wood materials with their deposit location.

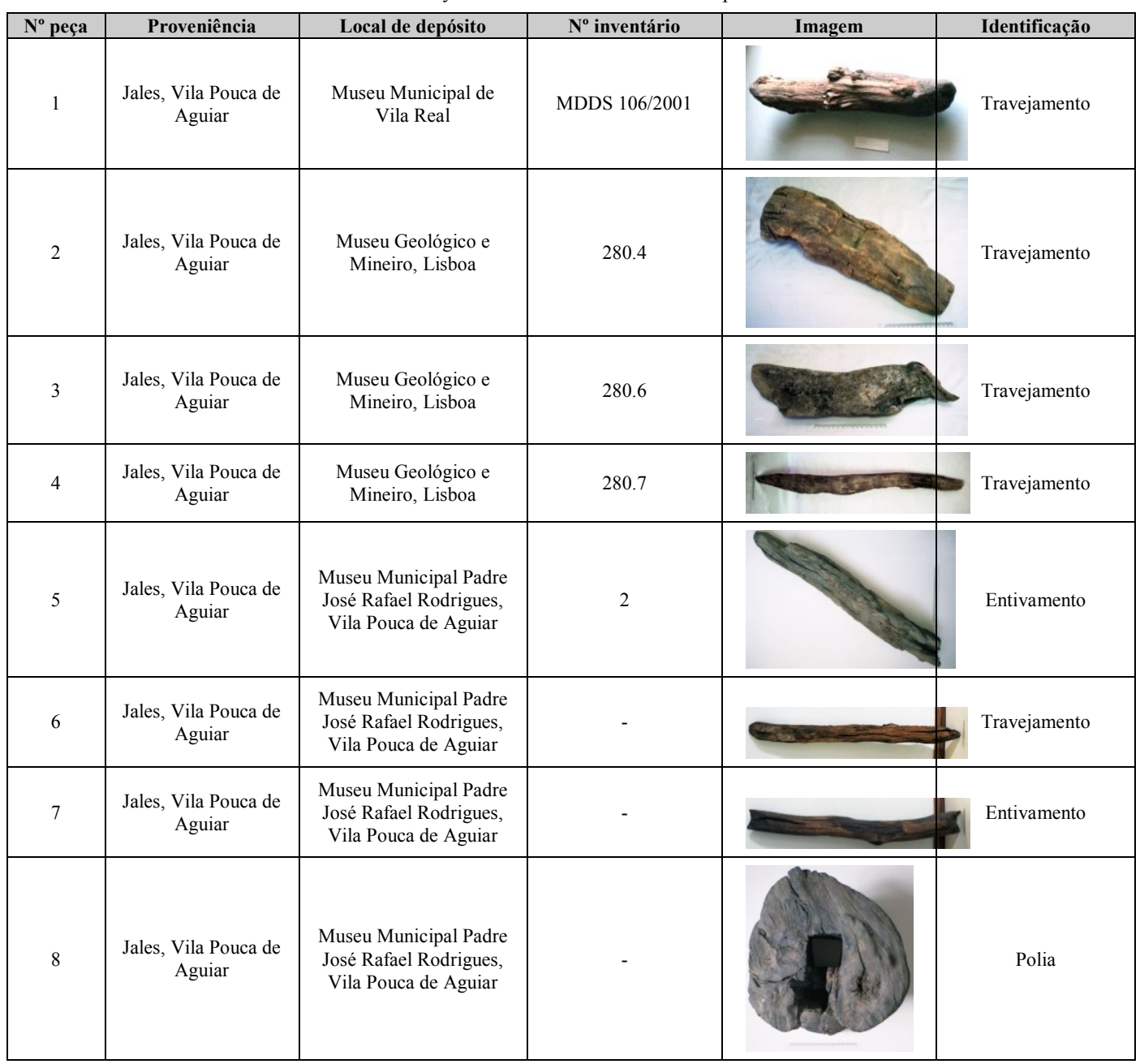




\begin{tabular}{|c|c|c|c|c|}
\hline 9 & $\begin{array}{l}\text { Jales, Vila Pouca de } \\
\text { Aguiar }\end{array}$ & $\begin{array}{l}\text { Museu Municipal Padre } \\
\text { José Rafael Rodrigues, } \\
\text { Vila Pouca de Aguiar }\end{array}$ & - & Bateia \\
\hline 10 & $\begin{array}{l}\text { Tresminas, Vila } \\
\text { Pouca de Aguiar }\end{array}$ & $\begin{array}{l}\text { LNEG, S. Mamede de } \\
\text { Infesta }\end{array}$ & - & Travejamento \\
\hline 11 & $\begin{array}{l}\text { Tresminas, Vila } \\
\text { Pouca de Aguiar }\end{array}$ & $\begin{array}{l}\text { LNEG, S. Mamede de } \\
\text { Infesta }\end{array}$ & - & Travejamento \\
\hline 12 & Algares, Aljustrel & $\begin{array}{l}\text { Museu Geológico e } \\
\text { Mineiro, Lisboa }\end{array}$ & 278.8 & Caleira \\
\hline 13 & Algares, Aljustrel & $\begin{array}{l}\text { Museu Geológico e } \\
\text { Mineiro, Lisboa }\end{array}$ & 278.9 & Entivamento \\
\hline 14 & Algares, Aljustrel & $\begin{array}{l}\text { Museu Geológico e } \\
\text { Mineiro, Lisboa }\end{array}$ & 278.10 & Entivamento \\
\hline 15 & Algares, Aljustrel & $\begin{array}{l}\text { Museu Geológico e } \\
\text { Mineiro, Lisboa }\end{array}$ & 278.11 & Entivamento \\
\hline 16 & Algares, Aljustrel & $\begin{array}{l}\text { Museu Geológico e } \\
\text { Mineiro, Lisboa }\end{array}$ & 278.12 & Travejamento \\
\hline 17 & Algares, Aljustrel & $\begin{array}{l}\text { Museu Geológico e } \\
\text { Mineiro, Lisboa }\end{array}$ & 278.13 & Travejamento \\
\hline 18 & Algares, Aljustrel & $\begin{array}{l}\text { Museu Geológico e } \\
\text { Mineiro, Lisboa }\end{array}$ & 278.14 & Travejamento \\
\hline 19 & Algares, Aljustrel & $\begin{array}{l}\text { Museu Geológico e } \\
\text { Mineiro, Lisboa }\end{array}$ & 278.30 .2 & Entivamento \\
\hline 20 & Algares, Aljustrel & $\begin{array}{l}\text { Museu Geológico e } \\
\text { Mineiro, Lisboa }\end{array}$ & 278.30 .2 & Travejamento \\
\hline 21 & Algares, Aljustrel & $\begin{array}{l}\text { Museu Geológico e } \\
\text { Mineiro, Lisboa }\end{array}$ & 278.61 & Escada \\
\hline 22 & Algares, Aljustrel & $\begin{array}{l}\text { Museu Nacional de } \\
\text { Arqueologia, Lisboa }\end{array}$ & 989.35 .2 & Escada \\
\hline 23 & Algares, Aljustrel & $\begin{array}{l}\text { Museu Nacional de } \\
\text { Arqueologia, Lisboa }\end{array}$ & 997.10 .13 & Escada \\
\hline 24 & Algares, Aljustrel & $\begin{array}{l}\text { Museu Nacional de } \\
\text { Arqueologia, Lisboa }\end{array}$ & - & Escada \\
\hline 25 & Algares, Aljustrel & $\begin{array}{l}\text { Museu Nacional de } \\
\text { Arqueologia, Lisboa }\end{array}$ & 989.35 .3 & Caleira \\
\hline 26 & Algares, Aljustrel & $\begin{array}{l}\text { Museu Geológico e } \\
\text { Mineiro, Lisboa }\end{array}$ & 278 & Entivamento \\
\hline
\end{tabular}




\begin{tabular}{|c|c|c|c|c|}
\hline 27 & Algares, Aljustrel & $\begin{array}{l}\text { Museu Nacional de } \\
\text { Arqueologia, Lisboa }\end{array}$ & 997.10 .8 & Polia \\
\hline 28 & Algares, Aljustrel & $\begin{array}{l}\text { Museu Nacional de } \\
\text { Arqueologia, Lisboa }\end{array}$ & 997.10 .7 & Polia \\
\hline 29 & Algares, Aljustrel & $\begin{array}{l}\text { Museu Nacional de } \\
\text { Arqueologia, Lisboa }\end{array}$ & 997.10 .10 & Elmento de sarilho \\
\hline 30 & Algares, Aljustrel & $\begin{array}{l}\text { Museu Nacional de } \\
\text { Arqueologia, Lisboa }\end{array}$ & 997.10 .9 & mento de sarilho \\
\hline 31 & Algares, Aljustrel & $\begin{array}{l}\text { Museu Geológico e } \\
\text { Mineiro, Lisboa }\end{array}$ & 278.5 & Maço \\
\hline 32 & Algares, Aljustrel & $\begin{array}{l}\text { Museu Geológico e } \\
\text { Mineiro, Lisboa }\end{array}$ & 278.4 & Bateia \\
\hline
\end{tabular}

Tabela 2. Características dos materiais estudados

Table 2. Characteristics of the studied objects.

\begin{tabular}{|c|c|c|c|c|c|c|c|c|}
\hline $\begin{array}{c}\mathrm{N}^{\circ} \\
\text { peça }\end{array}$ & Madeira & $\begin{array}{l}\text { Comprimento } \\
\text { máx. }(\mathrm{cm})\end{array}$ & $\begin{array}{c}\text { Largura } \\
\text { máx. }(\mathrm{cm})\end{array}$ & $\begin{array}{l}\text { Espessura } \\
\text { máx. }(\mathrm{cm})\end{array}$ & $\begin{array}{l}\text { Diâmetro } \\
\text { máx. (cm) }\end{array}$ & $\begin{array}{c}\text { Altura máx. } \\
(\mathrm{cm})\end{array}$ & Peso (g) & Referências \\
\hline 1 & carvalho & 66,7 & - & 8,6 & - & - & - & $\begin{array}{l}\text { MARTINS 2008, catálo- } \\
\text { go, p. } 168 \mathrm{n}^{\circ} 1.1 .\end{array}$ \\
\hline 2 & carvalho & 47,3 & 15,0 & 8,4 & - & - & - & $\begin{array}{l}\text { ALARCÃO 1997, p. } 112 \\
\mathrm{n}^{\circ} 12 ; \text { MARTINS } 2008, \\
\text { catálogo, p. } 168 \mathrm{n}^{\circ} 1.2 \text {. }\end{array}$ \\
\hline 3 & carvalho & 45,5 & 10,5 & 2,4 & - & - & - & $\begin{array}{l}\text { MARTINS } 2008 \text {, catálo- } \\
\text { go, p. } 168 \mathrm{n}^{\circ} 1.3 \text {. }\end{array}$ \\
\hline 4 & carvalho & 83,7 & 7,0 & 3,3 & - & - & - & $\begin{array}{l}\text { MARTINS } 2008 \text {, catálo- } \\
\text { go, p. } 168 \mathrm{n}^{\circ} 1.4 .\end{array}$ \\
\hline 5 & carvalho & 66,0 & 9,5 & - & - & - & 2132,26 & $\begin{array}{l}\text { ALARCÃO } 1997, \text { p. } 112 \\
\text { n }^{\circ} 15 ; \text { MARTINS } 2008, \\
\text { catálogo, p. } 169 \text { n }^{\circ} 1.5 .\end{array}$ \\
\hline 6 & carvalho & 137,0 & 12,0 & - & - & - & - & $\begin{array}{c}\text { Alarcão 1997, p. } 112 \\
\mathrm{n}^{\circ} 14 ; \text { Martins } 2008, \\
\text { catálogo, p. } 169 \text { n }^{\circ} 1.6 .\end{array}$ \\
\hline 7 & carvalho & 133,7 & 14,3 & - & - & - & - & $\begin{array}{c}\text { ALARCÃO } 1997, \text { p. } 112 \\
\text { n }^{\circ} 13 ; \text { MARTINS } 2008, \\
\text { catálogo, p. } 169 \text { n }^{\circ} 1.7 .\end{array}$ \\
\hline 8 & carvalho & 36,1 & 38,5 & - & - & c. 12,3 & - & $\begin{array}{l}\text { ALARCÃO 1997, p. } 113 \\
n^{\circ} 4\end{array}$ \\
\hline 9 & carvalho & 47,5 & & 1,5 & - & 9,8 & 1840,91 & $\begin{array}{c}\text { ALARCÃO 1997, p. } 109 \\
\mathrm{n}^{\circ} 4 ; \text { MARTINS } 2008, \\
\text { catálogo, p. } 172 \mathrm{n}^{\circ} \\
2.10 .\end{array}$ \\
\hline
\end{tabular}




\begin{tabular}{|c|c|c|c|c|c|c|c|c|}
\hline 10 & castanho & 54,9 & 10,5 & 4,2 & - & - & 841,30 & $\begin{array}{l}\text { MARTINS 2008, catálo- } \\
\text { go, p. } 200 \mathrm{n}^{\circ} 1.1 .\end{array}$ \\
\hline 11 & castanho & 69,6 & - & - & 7,7 & - & 1585,90 & $\begin{array}{l}\text { MARTINS 2008, catálo- } \\
\text { go, p. } 200 \mathrm{n}^{\circ} 1.1 \text {. }\end{array}$ \\
\hline 12 & azinho & 65,1 & 15,6 & 8,2 & - & $\begin{array}{l}- \\
-\end{array}$ & - & $\begin{array}{c}\text { ALARCÃo 1997, p. } 112 \\
\text { no } 2 \text {; DOMERGUE } 1983 \text {, } \\
\text { p. } 38 \text { no }^{\circ} 32 \text {; MARTINS } \\
\text { 2008, catálogo, p. } 385 \\
\text { no } 1.1 . ; \text { VIANA et al. } \\
\text { 1954, est. } 4 \text { fig. } 12 .\end{array}$ \\
\hline 13 & azinho & 117,1 & 14,0 & 4,5 & $\begin{array}{ll}- & - \\
-1\end{array}$ & - & - & $\begin{array}{l}\text { ALARCÃo 1997, p. } 112 \\
\text { no 10; DOMERGUE } \\
\text { 1983, p. } 37 \mathrm{n}^{\circ} 12 ; \\
\text { MARTINS } 2008 \text {, catálo- } \\
\text { go, p. } 385 \mathrm{n}^{\circ} 1.2 .\end{array}$ \\
\hline 14 & azinho & 105,2 & 13,5 & 4,5 & $\begin{array}{ll}- & - \\
\end{array}$ & - & - & 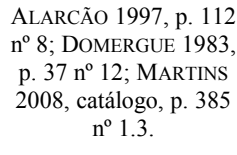 \\
\hline 15 & azinho & 101,0 & 14,5 & 4,5 & - & - & - & 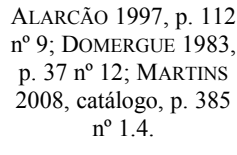 \\
\hline 16 & azinho & 54,0 & 13,0 & 5,0 & - & - & - & $\begin{array}{l}\text { ALARCÃO } 1997 \text {, p. } 112 \\
\text { no } 11 ; \text { DOMERGUE } \\
\text { 1983, p. } 37 \mathrm{n}^{\circ} 12 ; \\
\text { MARTINS } 2008 \text {, catálo- } \\
\text { go, p. } 386 \mathrm{n}^{\circ} 1.5 .\end{array}$ \\
\hline 17 & azinho & 45,7 & - & - & 33,1 & - & 1829,02 & $\begin{array}{l}\text { MARTINS } 2008 \text {, catálo- } \\
\text { go, p. } 386 \mathrm{n}^{\circ} 1.6 .\end{array}$ \\
\hline 18 & azinho & 75,5 & 15,5 & 15,0 & - & - & - & $\begin{array}{l}\text { ALARCÃo 1997, p. } 112 \\
\mathrm{n}^{\circ} 17 ; \text { MARTINS } 2008 \\
\text { catálogo, p. } 386 \mathrm{n}^{\circ} 1.7 .\end{array}$ \\
\hline 19 & azinho & 19,5 & 5,3 & - & - & - & 105,09 & $\begin{array}{l}\text { MARTINS } 2008 \text {, catálo- } \\
\text { go, p. } 386 \text { n }^{\circ} 1.8 \text {. }\end{array}$ \\
\hline 20 & azinho & 28,8 & 6,8 & - & - & - & 561,26 & $\begin{array}{l}\text { MARTINS 2008, catálo- } \\
\text { go, p. } 386 \text { n }^{\circ} 1.8 \text {. }\end{array}$ \\
\hline 21 & azinho & - & 33,0 & 13,5 & - & 102,0 & - & $\begin{array}{l}\text { MARTINS } 2008 \text {, catálo- } \\
\text { go, p. } 386 \mathrm{n}^{\circ} 1.9 \text {. }\end{array}$ \\
\hline 22 & azinho & - & 13,9 & - & - & 83,6 & - & $\begin{array}{c}\text { ALARCÃO 1997, p. } 111 \\
\text { no }^{\circ} \text {; DOMERGUE } 1983, \\
\text { p. } 37 \text { no }^{\circ} 20 ; \text { MARTINS } \\
\text { 2008, catálogo, p. } 387 \\
\text { n }^{\circ} 1.10 .\end{array}$ \\
\hline
\end{tabular}




\begin{tabular}{|c|c|c|c|c|c|c|c|c|}
\hline 23 & azinho & - & 15,4 & - & - & 96,5 & - & $\begin{array}{c}\text { ALARCÃO 1997, p. } 111 \\
\text { no }^{\circ} 5 \text {; DOMERGUE } 1983 \text {, } \\
\text { p. } 37 \text { no }^{\circ} 19 ; \text { MARTINS } \\
\text { 2008, catálogo, p. } 387 \\
\text { n }^{\circ} 1.11 .\end{array}$ \\
\hline 24 & azinho & - & 14,3 & 12,5 & - & 78,4 & - & $\begin{array}{c}\text { DOMERGUE 1983, p. } \\
37 \mathrm{n}^{\circ} 22 ; \text { MARTINS } \\
\text { 2008, catálogo, p. } 387 \\
\mathrm{n}^{\circ} 1.12 .\end{array}$ \\
\hline 25 & azinho & 102,0 & 21,1 & 12,5 & - & - & - & 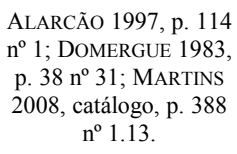 \\
\hline 26 & azinho & 139,5 & 84,5 & - & - & - & - & $\begin{array}{l}\text { MARTINS } 2008 \text {, catálo- } \\
\text { go, p. } 388 \mathrm{n}^{\circ} 1.14 \text {. }\end{array}$ \\
\hline 27 & azinho & 18,9 & 15,4 & - & - & 5,4 & 846,21 & $\begin{array}{c}\text { ALARCÃO 1997, p. } 113 \\
\text { no } 6 \text {; DOMERGUE 1983, } \\
\text { p. } 35 \text { no }^{\circ} 15 \text {; MARTINS } \\
\text { 2008, catálogo, p. } 388 \\
\text { n }^{\circ} 1.15 .\end{array}$ \\
\hline 28 & azinho & 22,0 & 21,5 & - & - & 6,2 & 953,89 & $\begin{array}{c}\text { ALARCÃO 1997, p. } 113 \\
\text { no } 5 \text {; DOMERGUE 1983, } \\
\text { p. } 37 \text { no }^{\circ} 16 \text {; MARTINS } \\
\text { 2008, catálogo, p. } 388 \\
\text { n }^{\circ} 1.16 .\end{array}$ \\
\hline 29 & carvalho & 34,4 & - & - & - & 7,9 & 1298,79 & $\begin{array}{l}\text { ALARCÃO 1997, p. } 111 \\
\mathrm{n}^{\circ} 4 \text {; Martins } 2008, \\
\text { catálogo, p. } 389 \mathrm{n}^{\circ} \\
1.17 .\end{array}$ \\
\hline 30 & carvalho & 35,2 & 8,6 & - & - & 9,5 & 1400,12 & $\begin{array}{l}\text { ALARCÃO 1997, p. } 111 \\
\mathrm{n}^{\circ} 3 ; \text { MARTINS } 2008, \\
\text { catálogo, p. } 389 \mathrm{n}^{\circ} \\
1.18 .\end{array}$ \\
\hline 31 & azinho & 31,4 & 11,6 & 9,2 & - & & 801,70 & $\begin{array}{c}\text { ALARCÃO 1997, p. } 110 \\
\mathrm{n}^{\circ} 7 \text {; DOMERGUE } 1983, \\
\text { p. } 38 \text { n }^{\circ} 33 \text {; MARTINS } \\
\text { 2008, catálogo, p. } 393 \\
\text { no 2.6.; VIANA et al. } \\
\text { 1954, est. } 5 \text { fig. } 15 .\end{array}$ \\
\hline 32 & azinho & 29,1 & 25,1 & - & - & 7,7 & 889,31 & $\begin{array}{c}\text { ALARCÃO 1997, p. } 109 \\
\mathrm{n}^{\circ} 6 \text {; DOMERGUE } 1983, \\
\text { p. } 37 \text { n }^{\circ} 25 \text {; MARTINS } \\
\text { 2008, catálogo, p. } 393 \\
\text { no 2.7.; VIANA et al. } \\
\text { 1954, est. } 3 \text { fig. } 10 .\end{array}$ \\
\hline
\end{tabular}

A análise da Tabela 1 mostra que os vestígios de madeira provêm de três sítios arqueológicos: dois no Norte de Portugal - Tresminas e Jales, e um no Sul - Algares, Aljustrel. Neste momento, fica apenas o registo através de fontes documentais das madeiras encontradas no Sul de Portugal - S. Domingos, Mértola (ALlAN 1965: 149, BragA 1961), já que as mesmas se encontram desaparecidas.

Toda a área compreendida entre Tresminas e Jales foi amplamente explorada no período romano para a extracção de ouro como minério principal. Os múltiplos vestígios arqueológicos conectados com a mineração foram atempadamente detectados, identifi- cados e estudados, principalmente por J. Wahl (1988, 1993, 1998), sendo uma área cuja preservação ainda hoje atrai os investigadores interessados neste tema (ALARCÃo 1987 e 1988, DOMERGUE 1987, MARTINS 2008 e 2017, REgULA WAHL-CLERICI et al. 2015, J. SÁNCHEZ-PALENCIA 2015). Actualmente encontramse identificados os principais trabalhos mineiros a céu aberto (trincheiras e cortas) e subterrâneos (galerias e poços), a rede hidráulica (canais, barragens, depósitos), os povoados mineiros de apoio directo à exploração, a necrópole, as lavarias e áreas relacionadas com a metalurgia - forno e escoriais (WAHL 1988, MARTINS 2008). 
Os materiais em madeira foram recolhidos aquando do desentulhamento das galerias romanas, sendo ainda possível observar in situ travejamentos submersos em alguns canais de escoamento de galerias, como por exemplo na galeria do Pilar, corta das Covas, Tresminas (Fig. 2).

O Sul de Portugal em época romana direcciona -se para a exploração do cobre. As explorações romanas nas minas de S. Domingos e Algares foram profusamente estudadas (ALLAN 1965, DOMERGUE
1983 e 2002), localizando-se na denominada Faixa Piritosa, com jazigos essencialmente de pirite cuprífera, calcopirite, blenda, galena e enxofre, entre outros, mas contendo valores anormais de ouro e prata nos chapéus de ferros (ANDRADE 1970, CARNEIRO 1998) (Fig. 3); assim, o ouro é também aproveitado não como minério principal, mas sim como secundário. Ambas explorações compreendem trabalhos a céu aberto e subterrâneos.

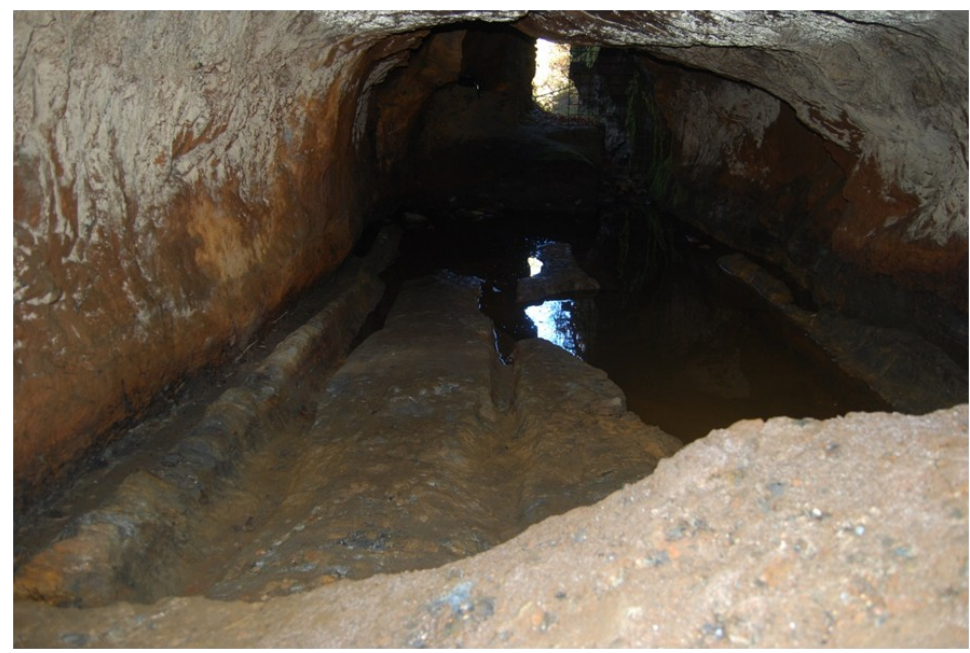

Fig. 2. Galeria do Pilar, corta das Covas, Tresminas, Vila Pouca de Aguiar.

Fig. 2. Gallery of Pilar, Tresminas, Vila Pouca de Aguiar.

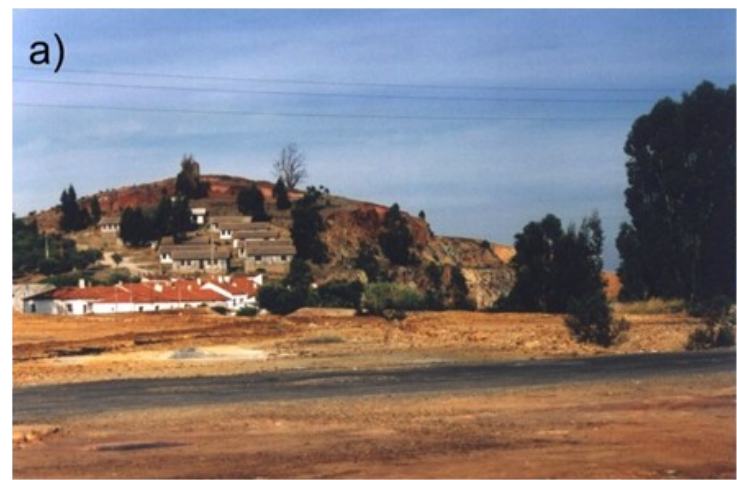

Fig. 3. Algares, Aljustrel: a) chapéu de ferro; b) escorial.

Fig. 3. Algares, Aljustrel: a) iron hat; b) slag area.

A cronologia atribuída às peças estudadas é a romana, o que se prende com vários factores:

- os locais de onde são provenientes as peças comportaram unicamente trabalhos de época romana, até ao momento de serem detectadas e/ou exumadas;

- os materiais conjuntamente exumados, cerâmicos entre outros, são datados deste período (MARTINS 2008).

No entanto, reconhece-se que as tipologias das madeiras e suas funcionalidades perduram ao

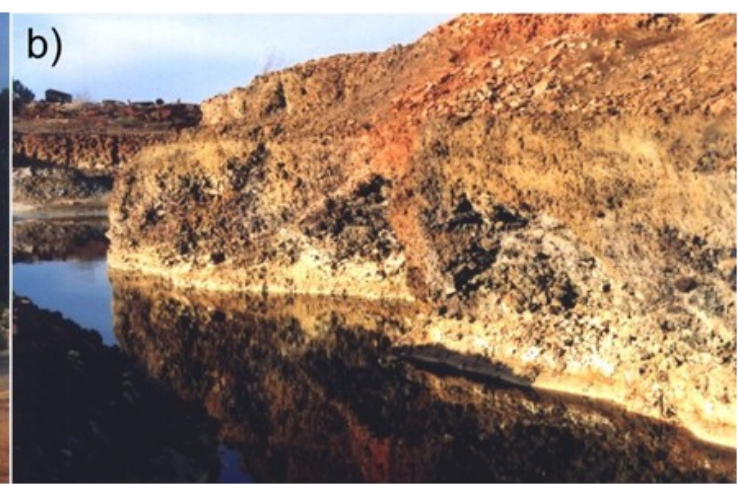

longo dos tempos, o que por vezes, em caso de dúvida, conduzirá à necessidade de uma datação mais precisa. Assim, por exemplo, em relação à polia com o $\mathrm{n}^{\circ} 8$, proveniente da Mina dos Mouros, Jales, foi realizada uma análise de datação por 14C, por J. Sánchez Palencia (2015: 190), cujo resultado revelou: 1953 \pm 33 BP (Angström Laboratory, Uppsala Universitet, Ua-49927, JAL-01 2014).

Sendo as análises laboratoriais dispendiosas, aceita-se que uma boa classificação de materiais arqueológicos poderá permitir uma datação adequada. 


\section{A MADEIRA NA EXPLORAÇ̃̃O MINEIRA}

A madeira podia ter várias funções: elementos de construção, produção de objectos e encabamento de instrumentos mineiros.

Como elemento de construção, a madeira servirá para a elaboração de entivações. Os constrangimentos no interior de uma mina subterrânea são muitos, compreendendo numerosos desabamentos quando os solos não são estáveis; daí a necessidade de entivar galerias e poços com travejamentos de madeira, sendo por vezes o seu formato adequado a essa inibição, como seja secções quadrangulares, rectangulares ou trapezoidais (MARTINS 2008: 83). Nos materiais estudados, de acordo com suas características, fez-se a distinção entre entivamento - tábua em madeira destinada a revestir uma parede / hasteal ou tecto de galeria ou poço com o fim de impedir desabamentos (peças com os números $5,7,13,14,15,19,26)$, e travejamento - tábua em madeira que poderá ter o fim de entivamento ou não (peças com os números 1, 2, 3, $4,6,10,11,16,17,18,20)$. Coloca-se em ponderação as peças com os números 4,10 e 11 , que poderiam ter servido para estacamento, já que são pontiagudas numa das extremidades (Tabela 3 ).

Tabela 3. Identificação dos elementos em madeira para construção.

Table 3. Identification of the wood materials for construction.

\begin{tabular}{|c|c|c|c|c|}
\hline $\mathbf{N}^{0}$ peça & Proveniência & Identificação & Encaixe & União \\
\hline 1 & Jales & Travejamento & - & - \\
\hline 2 & Jales & Travejamento & Em T com caixa e espiga & - \\
\hline 3 & Jales & Travejamento & - & - \\
\hline 4 & Jales & Travejamento & - & - \\
\hline 5 & Jales & Entivamento & Simples por montagem sobreposta & - \\
\hline 6 & Jales & Travejamento & Em T com caixa e espiga & - \\
\hline 7 & Jales & Entivamento & Em T com espiga e forquilha & - \\
\hline 10 & Tresminas & Travejamento & - & Cavilhas \\
\hline 11 & Tresminas & Travejamento & - & - \\
\hline 13 & Algares & Entivamento & Simples por montagem sobreposta & Pregos \\
\hline 14 & Algares & Entivamento & Simples por montagem sobreposta & Pregos \\
\hline 15 & Algares & Entivamento & Em T com espiga e forquilha & Pregos \\
\hline 16 & Algares & Travejamento & - & Pregos \\
\hline 17 & Algares & Travejamento & Simples por montagem sobreposta & - \\
\hline 18 & Algares & Travejamento & - & Pregos \\
\hline 19 & Algares & Entivamento & Simples por montagem sobreposta & - \\
\hline 20 & Algares & Travejamento & - & - \\
\hline 26 & Algares & Entivamento & Em T com espiga e forquilha & Pregos \\
\hline
\end{tabular}

A historiografia revela-nos a presença de entivamentos na mina dos Mouros, Jales, e em Algares, Aljustrel: na mina dos Mouros, aquando da abertura das minas contemporâneas ter-se-ão descobertos poços romanos de secção quadrangular, entivados com madeira de pinheiro e carvalho, cujos compri- mentos variavam entre os $0,80 \mathrm{~m}$ e $1,00 \mathrm{~m}$, segundo testemunhos orais (MARTINS 2008: catálogo ficha $\mathrm{n}^{\mathrm{o}}$ 18), e nas minas de Algares, Aljustrel, foram encontrados vários poços de secção quadrangular entivados (ANDRADE 1970: 277).

Os testemunhos orais dados por antigos traba- 
lhadores presentes à data dos desbravamentos contemporâneos nas minas de Jales (Mina dos Mouros) são uma mais-valia, principalmente tendo em conta que as madeiras referidas se encontram desaparecidas. Esta situação coloca obviamente dificuldades aos investigadores no que toca à sua identificação. Contudo, parecem credíveis aqueles testemunhos, uma vez que os trabalhadores na exploração mineira estando habituados a identificar os filões, de certeza também distinguiriam minimamente os diferentes tipos de madeira utilizadas, pelo menos as mais comuns.

As estruturas criadas para este fim - entivação, são rígidas, e a sua solidez, resistência e estabilidade dependem da disposição e organização dos materiais usados, neste caso das tábuas em madeira; um dos elementos muito importantes neste processo é o sistema de encaixe das tábuas e subsequente junção ou união. Daí que, sempre que possível, se tentou aferir qual o sistema de encaixe utilizado, trabalho não facilitado pela abundância de termos aplicados para uma mesma situação, sendo dominantes os seguintes:

a) Encaixe em $\mathrm{T}$ com caixa e espiga - uma das tábuas comporta uma "caixa", ou seja um entalhe, normalmente quadrangular, rebaixado, na qual encaixará uma das extremidades de uma outra tábua que também terá de ter o mesmo formato, ou seja uma ponta quadrangular saliente com a mesma profundidade da caixa (ULRICH 2007: 62 fig. 4.2.). É o caso das peças com os números 2 e 6 .

b) Encaixe simples por montagem sobreposta, de meia madeira em ângulo, o que normalmente traduz uma resistência média. Este sistema apesar de não muito "seguro", pelo menos aparentemente, foi largamente utilizado no período romano, como se verifica no exemplo de Camulodunum, séc. I a.C., actual Colchester, Inglaterra (ULRICH 2007: 71 fig. 4.12.).

c) Encaixe em $\mathrm{T}$ com espiga e forquilha, normalmente junta de canto, em que uma das tábuas tem uma ou as duas extremidades bifurcadas, e a(s) outra(s) tábua(s) têm a(s) ponta(s) saliente(s) para encaixar na primeira (ULRICH 2007: 62 fig. 4.2.). São exemplo as peças com os números 7 e 26 .

Idealmente, o sistema de encaixe seria de tal forma preciso que não necessitaria de alguma união (iunctura) (UlRICH 2007: 59). Contudo, é comum a utilização de pregos, cavilhas, cravos, como se constata nas peças com os números $10,13,14,15$, 16,18 e 26.

Os trabalhos a céu aberto também poderiam ser escorados ou entivados. Segundo A. M. Nogueira (1936: 202) era utilizado um esquema em H, compreendendo dois toros aplanados, cuja parte plana ficaria voltada para as hasteais da trincheira, e a parte convexa (ou outro lado) comportaria encaixes (em caixa ou perfuração) para introdução do elemento perpendicular com extremidades pontiagudas ou em espiga, o que poderá ser o caso das peças inventariadas com os números 6 e 17, ambas pontiagudas numa das extremidades, tendo a primeira no outro extremo um encaixe em $\mathrm{T}$ com caixa e espiga (caixa quadrangular com $7 \mathrm{~cm}$ de lado e $2 \mathrm{~cm}$ de profundidade), e a segunda um encaixe simples por montagem sobreposta.

Mas com madeira também se constroem objectos, e os que foram detectados encontram-se conectados com acessos a galerias e poços, máquinas de elevação e instrumentos mineiros (Tabela 4).

Tabela 4. Objectos em madeira.

Table 4. Wooden objects.

\begin{tabular}{|c|c|c|c|}
\hline $\mathrm{N}^{0}$ peça & Proveniência & Identificação & Função \\
\hline 8 & Jales & Polia & Máquina de elevação \\
\hline 9 & Jales & Bateia & Instrumento mineiro \\
\hline 21 & Aljustrel & Escada & Acesso / descida a galerias / poços \\
\hline 22 & Aljustrel & Escada & Acesso / descida a galerias / poços \\
\hline 23 & Aljustrel & Escada & Acesso / descida a galerias / poços \\
\hline 24 & Aljustrel & Escada & Acesso / descida a galerias / poços \\
\hline 27 & Aljustrel & Polia & Máquina de elevação \\
\hline 28 & Aljustrel & Polia & Máquina de elevação \\
\hline 29 & Aljustrel & Elemento sarilho & Máquina de elevação \\
\hline 30 & Aljustrel & Elemento sarilho & Máquina de elevação \\
\hline 31 & Aljustrel & Maço & Instrumento mineiro \\
\hline 32 & Aljustrel & Bateia & Instrumento mineiro \\
\hline
\end{tabular}


O interior de uma mina poderá ser visto como um "queijo suíço" constituído por uma profusão de galerias e poços de grande versatilidade funcional, como seja permitir o acesso ao interior de uma mina, o arejamento das galerias e o avanço dos trabalhos de patamar em patamar, por vezes atingindo-se profundidades de $60 \mathrm{~m}$ como é o caso da galeria da Transtagana no jazigo de Algares, Aljustrel, e mesmo $150 \mathrm{~m}$ na mina dos Mouros, Jales (MARTINS 2008: catálogo ficha $\mathrm{n}^{\circ}$ 55).

Neste contexto são necessárias escadas que poderão ser escavadas na rocha (Fig. 4), ou feitas em madeira como é o caso das peças com os números 21, 22, 23 e 24. Estas poderiam simplesmente ser apoiadas no chão e ligeiramente inclinadas contra uma hasteal, ou mesmo presas a outras estruturas de madeira, se houver entivação, de que é exemplo um poço em Algares, Aljustrel (VIANA et al. 1954: 81). Como exemplo desta última situação é o caso do artefacto identificado com o número 21 e que ainda apresenta pregos.

As escadas em madeira estudadas apresentam tamanhos variáveis dependentes das necessidades, sendo constituídas normalmente por três degraus (peças completas), exceptuando a peça com o número 23 que já só comporta dois, o que poderá eventualmente dever-se ao seu muito mau estado de conservação (Tabela 5).

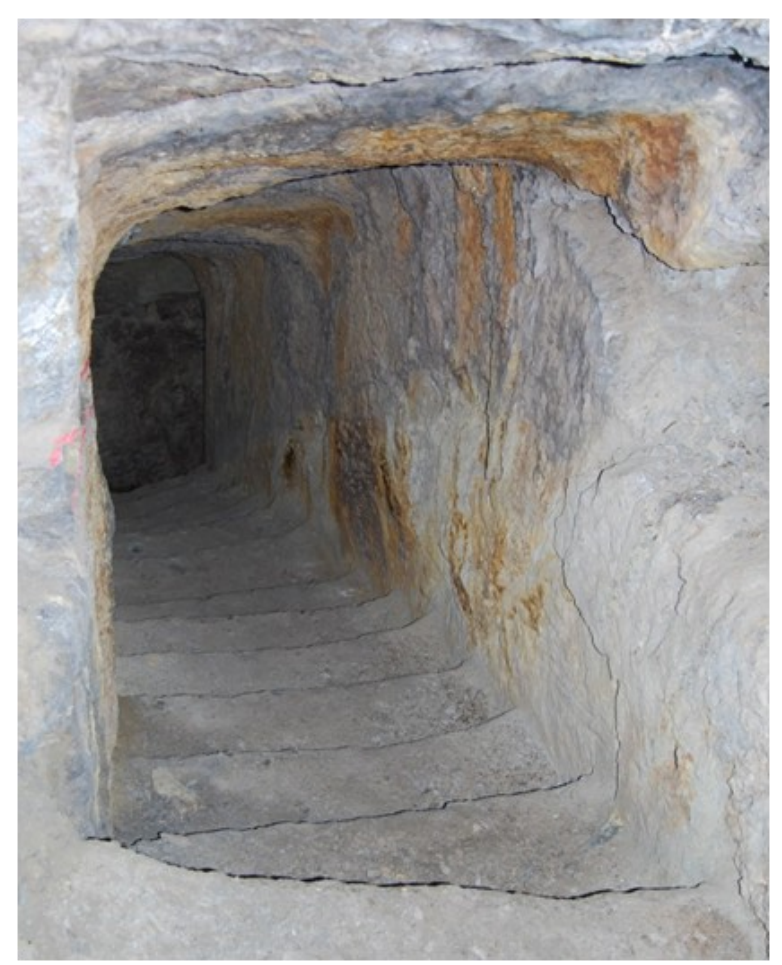

Fig. 4. Escada escavada na rocha na galeria dos Alargamentos, corta das Covas, Tresminas.

Fig. 4. Stair excavated in rock of the gallery of Alargamentos, Tresminas.

\begin{tabular}{l} 
Tabela 5. Características das escadas provenientes de Algares, Aljustrel. \\
Table 5. Characteristics of the wooden stairs from Algares, Aljustrel. \\
\cline { 2 - 6 } \\
\cline { 2 - 6 } \\
\cline { 2 - 6 }
\end{tabular}


As profundidades dos degraus variam entre os $2,6 \mathrm{~cm}$ e os $8,0 \mathrm{~cm}$, sendo o mais comum dimensões entre os $4,5 \mathrm{~cm}$ e os $5,7 \mathrm{~cm}$.

Devido às já mencionadas profundidades de mineração subterrânea eram vulgarmente atingidos níveis freáticos e lençóis de água, tornando-se por isso imperioso escoar as águas para fora das galerias através de canais de escoamento, ou bombear com o auxílio de máquinas de elevação. Acabam por ser estruturas móveis, mas resistentes, cujos elementos interligados permitiam a realização de movimentos.

Vitrúvio, na sua obra Tratado de Arquitectura (X.I.1 como citado em MACIEL 2006) faz a definição de máquina: «Consiste a máquina numa coesa aparelhagem de madeira que proporciona as maiores vantagens para a movimentação de cargas. Trabalha rotativamente seguindo a solução técnica dos círculos...». De facto, estes engenhos partem de princípios básicos como o da alavanca e sarilho (Vitrúvio X.II.2 como citado em MACIEL 2006), cunha, parafuso, roldana (Vitrúvio X.II.3 como citado em MACIEL 2006), cadernal (Vitrúvio X.II.4, como citado em MACIEL 2006), tambor (Vitrúvio X.II.5 como citado em MACIEL 2006) e cabrestante (Vitrúvio X.II.1 como citado em MACIEL 2006); o fundamento da utilização da alavanca: "dá-me um ponto de apoio e eu levantarei o mundo", que Arquimedes aperfeiçoa (MARTINS 2008: 88).

As máquinas de elevação pressupõem a força de tracção dos braços presos com espias, utilizando o princípio da alavanca, roldana e plano inclinado (MARTINS 2008: 88). Na mina de S. Domingos foram encontradas numa das galerias de esgoto dez rodas de madeira de azinho, dispostas em par por cinco patamares, providas com baldes para fazer o escoamento até à superfície da água (ALLAN 1965: 149). Infelizmente, resta-nos apenas o registo historiográfico. Um outro tipo de máquina accionada por cabrestante é referida por J. Wahl como tendo sido usado na galeria do Pilar, Tresminas (WAHL 1988), de que restam apenas os negativos das estruturas de madeira utilizadas.

As polias - roldanas, inventariadas com os números 8 (Jales), 27 e 28 (Aljustrel) terão feito parte de máquinas de elevação de águas, assim como as peças com os números 29 e 30 (Aljustrel), possivelmente fazendo parte de um sarilho, como os quatro detectados e referenciados na historiografia na mina de Algares, Aljustrel (VIANA et al. 1954: 81), ou cabrestante.

As bateias como as encontradas em Jales (peça número 9) e Aljustrel (peça número 32) seriam para batear as areias dos leitos dos rios ou de depósitos secundários - garimpo (em jazigos secundários), ou para ajudar na separação gravítica do minério no decurso da sua lavagem, uma vez que que as areias menos densas que o ouro sobrenadam, são removidas, e o ouro mais denso concentra-se no fundo (MARTINS 2008: 96).

G. Agrícola faz a ilustração deste processo, revelando bateias normalmente de forma circular (HoOver \& HoOver 1950: 157), mas que poderão ter outros formatos, como o das peças estudadas que é rectangular.

Inerente a todo este processo de mineração são imprescindíveis instrumentos mineiros que auxiliem o trabalhador na sua árdua tarefa de partir pedra: picos / picos-martelo com tipologias várias, cunhas e ponteiros, foices, entre outros. Devido à sua função seriam peças em ferro com um cabo em madeira, e que por razões óbvias seria frequentemente substituído (Fig. 5). Mas também existiriam instrumentos produzidos na sua totalidade em madeira, como um rodo em madeira de azinho proveniente das minas de Aljustrel (ALARCÃo 1997: $116 \mathrm{n}^{\circ}$ 8) e o maço com o número $31 \mathrm{com}$ a mesma proveniência.

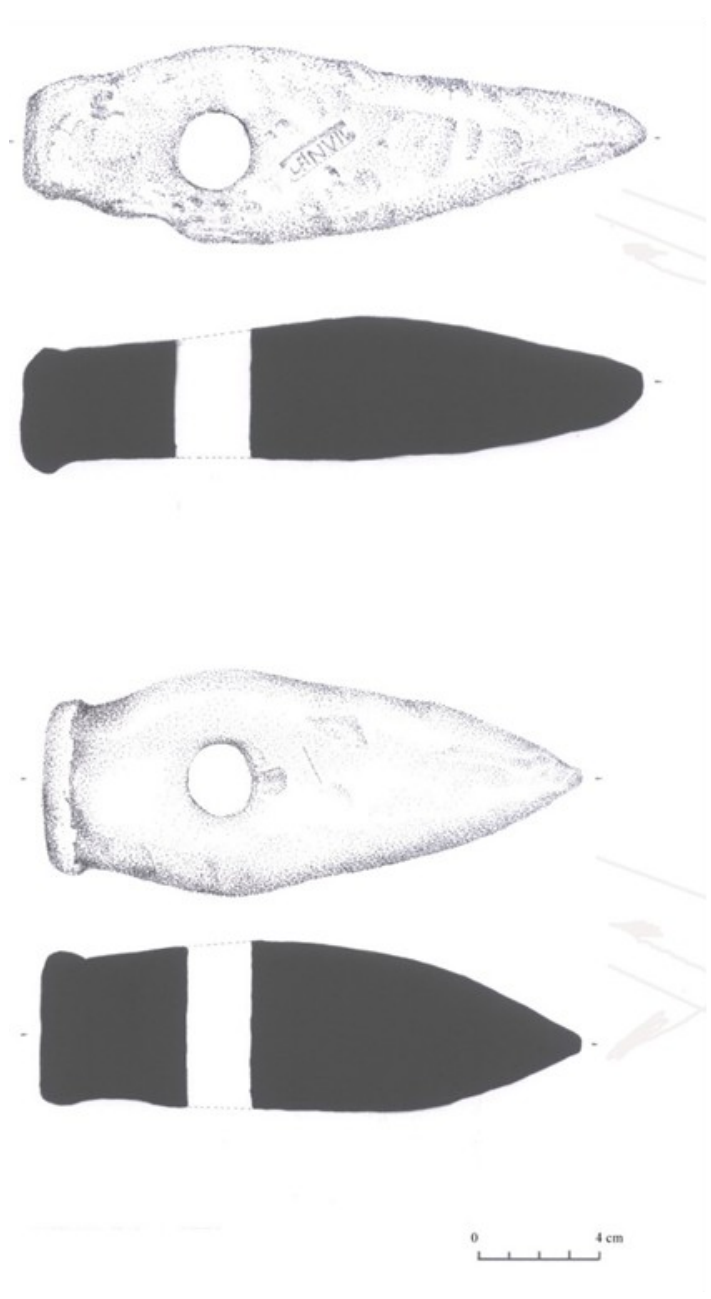

Fig. 5. Exemplos de picos em ferro provenientes da mina dos Mouros, Jales (MARTINS 2008: catálogo ficha $n^{\circ} 18$ fig. 13).

Fig. 5. Examples of iron malleus from the mine of Mouros, Jales (MARTINS 2008: catálogo ficha $n^{\circ} 18$ fig. 13). 


\section{A MADEIRA NA METALURGIA}

Como já mencionado no ponto anterior, a madeira também é precisa para o tratamento do minério; após a sua separação e trituração, o minério era lavado e efectuava-se uma decantação para uma separação gravítica, cujos tabuleiros ou estruturas de apoio seriam em madeira, tal como ilustrado por G. Agrícola (HoOver \& HoOver 1950: 291) (Fig. 6).
Para interligar os tabuleiros em diferentes patamares utilizar-se-iam pequenos canais ou caleiras em madeira como os inventariados com os números 12 e 25, provenientes de Aljustrel. Para que não houvesse deslocamentos essas caleiras seriam unidas às estruturas existentes através de pregos, como os presentes na caleira com o número 12 .

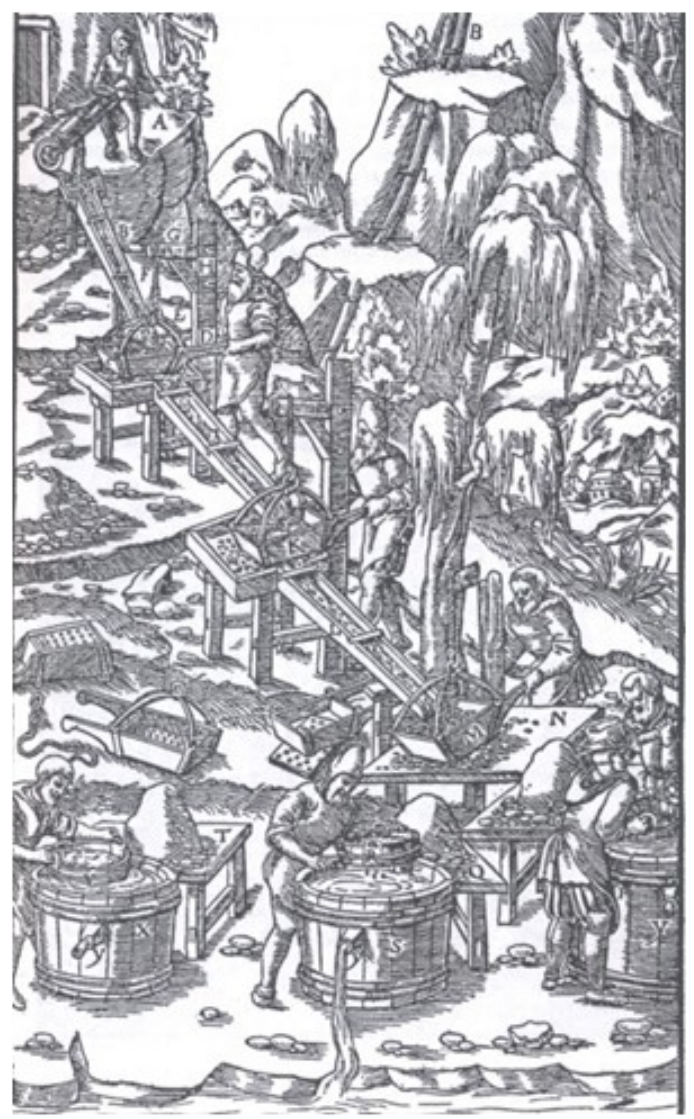

Fig. 6. Separação gravítica do minério (HOOVER \& HOOVER 1950: 291).

Fig. 6. Gravitic separation of ore (HOOVER \& HOOVER 1950: 291).

Tabela 6. Peças em madeira articuladas com o tratamento do minério. Table 6. Wooden objects connected with ore treatment.

\begin{tabular}{|c|c|c|c|}
\hline $\mathbf{N}^{\mathbf{0}}$ peça & Proveniência & Identificação & Sistema de encaixe com outros elementos \\
\hline 12 & Aljustrel & Caleira & Pregos \\
\hline 25 & Aljustrel & Caleira & - \\
\hline
\end{tabular}

O processo metalúrgico culmina com a redução do metal contido no minério à forma metálica, sendo para isso necessários fornos (MARTINS 2008: 100). E, uma vez mais, nesta fase é indispensável a madeira / carvão vegetal como combustível para os fornos, atendendo a que as transformações químicas pretendidas exigem temperaturas elevadas e uma atmosfera redutora.
As habituais evidências arqueológicas da utilização daqueles materiais de índole vegetal nos fornos advém da observação de enegrecimento no seu interior (Fig. 7a) resultante da deposição de carbono. As análises por MEV/EDX desse revestimento em amostras recolhidas no tecto do forno de Jales (MARTINS 2017, prelo) mostra a presença de uma estrutura filamentar contendo partículas metá- 
licas na ponta, típica dos "whiskers" de carbono catalisados pelo ferro (Fig. 7b) (LOBO \& TRIMM 1977). A identificação do carbono ratifica a utilização de um combustível vegetal, estando a sua deposição associada às temperaturas elevadas e ao equilíbrio C-CO- $\mathrm{CO}_{2}$ (reacção de Boudouard) responsável pelas condições redutoras no interior do forno.

A maioria dos fornos de metalurgia, independentemente de serem usados para o ouro ou não, são completamente limpos no final de cada operação (HUYSECOM \& AGUSTONI 1996, MARTINS 2008: 101). Assim, a inexistência de quaisquer resíduos torna praticamente impossível a identificação do tipo de combustível vegetal por estudos de arqueobotânica. Deste modo, são de extrema importância as informações colhidas nas fontes clássicas de identificação do tipo de combustível, como seja as de Plínio e Vitrúvio, assim como observações por MEV/EDX ou outras técnicas equivalentes na averiguação da presença de elementos químicos nos depósitos de carbono. A detecção daqueles elementos nestes sedimentos pode permitir estabelecer uma correlação com a composição mineralógica dos minérios ou com o próprio combustível vegetal. Como exemplo, nesta última situação refere-se o caso da Alyssum serpyllifolium subsp. Lusitanicum que demonstra capacidade para acumular níquel em solos serpentinitos como o do Complexo Ofiolítico de Morais e Bragança (MoRAIS et al. 2015).
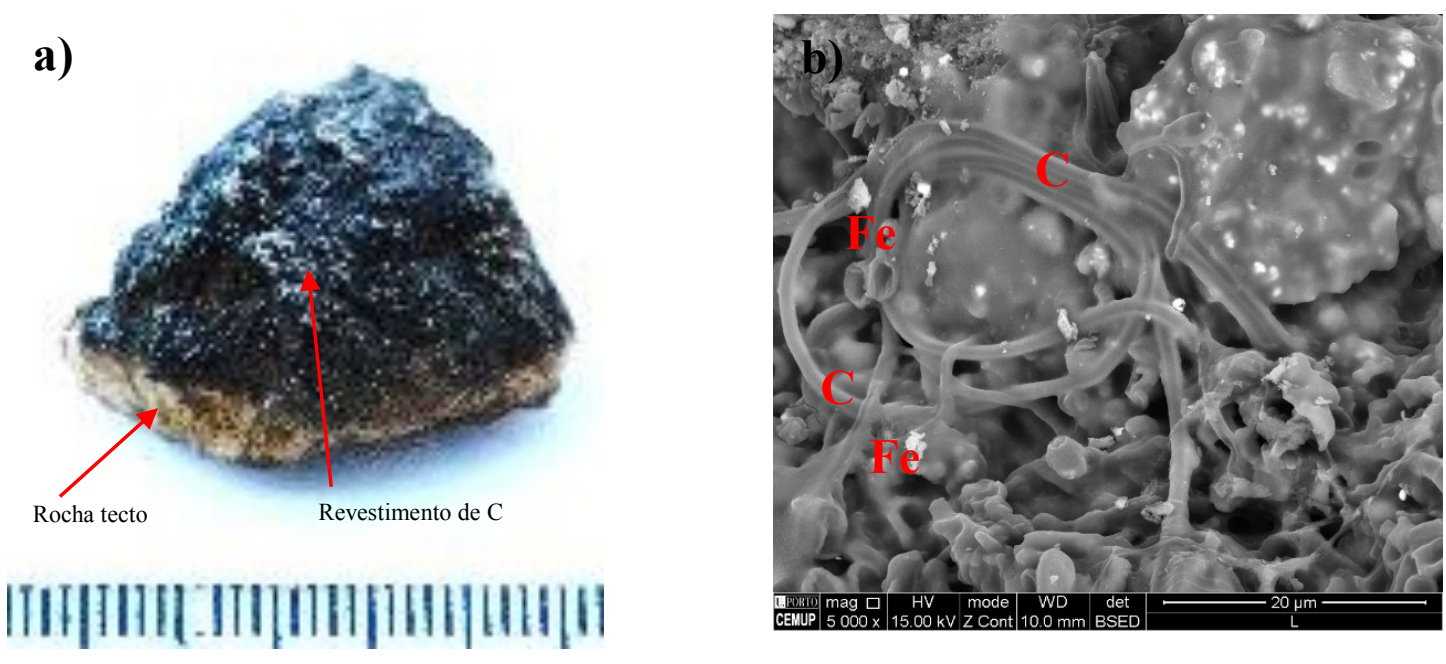

Fig. 7. a) Amostra do interior do tecto do forno de Jales; b) Fotomicrografia de electrões rectrodifundidos do revestimento mostrando os filamentos de carbono com Fe na ponta.

Fig. 7. a) Interior sample of the roof of the furnace of Jales; b) Backscattering electrons photomicrography of the coating showing the carbon whiskers with Fe at the tip.

\section{CARACTERIZAÇÃo DAS MADEIRAS UTILI- ZADAS}

As diferentes madeiras existentes comportam características muito próprias, o que possibilita a sua utilização nos mais diversos fins. Segundo Teofrasto, na sua obra Historia Plantarum (V, passim como citado em ULRICH 2007: 240) será necessário ter em conta a densidade vs. porosidade, a dureza vs. maciez, e o peso vs. leveza da madeira, considerando que as mais densas, duras e pesadas são as que nascem espontaneamente $(\mathrm{V}, 3.1$, como citado em ULRICH 2007: 240). Também Plínio na sua obra História Natural (XVI. 219 como citado em BosTOCK \& RILEY 1855) faz referência à qualidade das madeiras existentes, considerando que a de amieiro é capaz de sustentar grandes pesos, enquanto as melhores para ambientes húmidos seriam não só as do amieiro, mas também as de larício e carvalho, tal como Vitrúvio (II, IX como citado em MACIEL 2006).
De acordo com os critérios apontados, Teofrasto (V como citado em UlRICH 2007: 240) e Plínio (XVI como citado em BosTOCK \& RILEY 1855) classificam os diferentes tipos de madeira do seguinte modo: como mais densas e pesadas o ébano, sobreiro, larício e lótus; seguidamente o carvalho, laburnum, terebinto e corniso; como cada vez mais poroso e leve a azinheira, oliveira, carvalho silvestre e castanheiro; e finalmente, no extremo oposto, o choupo, o álamo, o abeto, a macieira e a tília. Do mesmo modo, Vitrúvio cataloga as diferentes madeiras adoptando no entanto um critério conectado com os quatro elementos da natureza (ULRICH 2007: 241): a terra simbolizando a dureza (quanto mais terra maior a dureza), o ar a densidade (quanto mais ar menor a densidade), o fogo a porosidade (quanto mais fogo maior é a porosidade) e a água a resistência (quanto mais água menor a resistência mecânica) (Tabela 7). 
Tabela 7. Características das diferentes madeiras segundo Vitrúvio (livro II, IX como citado em MACIEL 2006). Table 7. Timber characterization as described by Vitruvius (book II, IX as mentioned in MACIEL 2006).

\begin{tabular}{|c|c|c|c|c|c|c|c|}
\hline Madeira & Terra & $\mathbf{A r}$ & Fogo & Água & Deterioração & $\begin{array}{c}\text { Resistência ao } \\
\text { fogo }\end{array}$ & Flexibilidade \\
\hline Abeto & $\mathrm{XX}$ & $\mathrm{XXX}$ & $\mathrm{XXX}$ & $\mathrm{X}$ & $\mathrm{XXX}$ & 0 & - \\
\hline Agnocasto & $\mathrm{X}$ & XXX & $\mathrm{XXX}$ & $\mathrm{XX}$ & - & - & - \\
\hline Álamo & $\mathrm{XX}$ & XXX & XXX & $\mathrm{X}$ & $\mathrm{XX}$ & - & \\
\hline Carpa & $\mathrm{X}$ & XXX & $\mathrm{X}$ & XXX & - & - & - \\
\hline $\begin{array}{l}\text { Carvalho - } \\
\text { quercus }\end{array}$ & XXX & $\mathrm{X}$ & $\mathrm{X}$ & $\mathrm{X}$ & $\mathrm{X}$ & - & - \\
\hline $\begin{array}{l}\text { Carvalho - } \\
\text { aesculus }\end{array}$ & $\mathrm{XX}$ & $\mathrm{XX}$ & $\mathrm{XX}$ & $\mathrm{XX}$ & $\mathrm{XXX}$ & - & - \\
\hline $\begin{array}{l}\text { Carvalho - } \\
\text { cerrus }\end{array}$ & $\mathrm{XX}$ & XXX & $\mathrm{XX}$ & $\mathrm{XX}$ & $\mathrm{XXX}$ & - & - \\
\hline Cedro & $\mathrm{XX}$ & $\mathrm{XX}$ & $\mathrm{XX}$ & $\mathrm{XXX}$ & $\mathrm{XX}$ & - & $\mathrm{XXX}$ \\
\hline $\begin{array}{l}\text { Choupo } \\
\text { branco }\end{array}$ & $\mathrm{X}$ & $\mathrm{XXX}$ & $\mathrm{XXX}$ & $\mathrm{XX}$ & - & - & - \\
\hline $\begin{array}{l}\text { Choupo } \\
\text { negro }\end{array}$ & $\mathrm{X}$ & $\mathrm{XXX}$ & $\mathrm{XXX}$ & $\mathrm{XX}$ & - & - & - \\
\hline Cipreste & $\mathrm{XX}$ & $\mathrm{XX}$ & $\mathrm{XX}$ & $\mathrm{XXX}$ & $\mathrm{X}$ & - & XXX \\
\hline Faia & $\mathrm{XX}$ & XXX & $\mathrm{XX}$ & $\mathrm{XX}$ & $\mathrm{XXX}$ & - & - \\
\hline Freixo & $\mathrm{XX}$ & $\mathrm{X}$ & $\mathrm{X}$ & $\mathrm{XXX}$ & $\mathrm{XX}$ & - & - \\
\hline Junípero & $\mathrm{XX}$ & $\mathrm{XX}$ & $\mathrm{XX}$ & $\mathrm{XXX}$ & $\mathrm{XX}$ & - & $\mathrm{XXX}$ \\
\hline Larício & $\mathrm{XX}$ & $\mathrm{X}$ & $\mathrm{X}$ & $\mathrm{XX}$ & $\mathrm{X}$ & $\mathrm{XXX}$ & - \\
\hline Olmo & $\mathrm{XX}$ & $\mathrm{X}$ & $\mathrm{X}$ & $\mathrm{XXX}$ & $\mathrm{XX}$ & - & - \\
\hline Pinheiro & $\mathrm{XX}$ & $\mathrm{XX}$ & $\mathrm{XX}$ & XXX & $\mathrm{X}$ & - & $\mathrm{XXX}$ \\
\hline Salgueiro & $\mathrm{X}$ & XXX & XXX & $\mathrm{XX}$ & - & - & - \\
\hline Tília & $\mathrm{X}$ & $\mathrm{XXX}$ & XXX & $\mathrm{XX}$ & - & - & - \\
\hline Legenda: & & & & & & & \\
\hline
\end{tabular}

De salientar que algumas das madeiras referidas por Vitrúvio, como aesculus e cerrus, não detêm actualmente paralelos nas espécies actuais. Daí que na Tabela 7, apesar de comportar os nomes comuns (tal como referido em termos de critério na Introdução) optou-se no caso do carvalho por colocar a terminologia utilizada por Vitrúvio.

Os objectos provenientes das explorações mineiras de Tresminas são em madeira de castanheiro, que segundo Plínio é durável, de média qualidade e flexível, sendo no entanto limitada por facilmente se fracturar (ULRICH 2007: 256). Provavelmente este último dado terá influenciado na escolha das madeiras nas minas de Jales. Esta madeira é mais densa e dura, e salienta-se que um poste de $10 \mathrm{~cm}$ de diâmetro em madeira de carvalho demora cerca de 30 anos a perder as suas propriedades estruturais, enquanto um de pinheiro só dura cerca de 10 anos (ULRICH 2007: 261).

A azinheira é uma madeira densa e dura como o carvalho, mas muito resistente à fricção e passível de ser cortada em finas lâminas apesar do seu grão complexo (Plínio XVI. 229 como citado em BosTOCK \& RILEY 1855); as suas características tornam esta madeira boa para a construção de rodas, tal como as que foram encontradas nas minas de $\mathrm{S}$. Domingos, apesar de se deformar facilmente quando em ambiente muito seco. 
Um dos elementos determinantes na escolha da madeira a utilizar, para além da sua dureza e densidade, é também a sua capacidade de resistência à degradação e ao fogo, o que poderá estar relacionado com uma alta densidade e escassa porosidade (Tabela 7).

A deterioração das madeiras está dependente da presença de água e/ou humidade que contribui para o desenvolvimento de fungos e consequente podridão desta matéria-prima. Este conhecimento já adquirido em época romana era contornado por tratamentos de preservação: a madeira era colocada numa sala com fumo (fumarium) para que a sua adsorção a protegesse (ULRICH 2007), algo que também é referido por Vitrúvio (I,V.3 como citado em MACIEL 2006); este último ainda alude a utilização de certas resinas e óleos na preservação das madeiras, como sejam as resinas de cipreste e pinheiro (II,IX.12 como citado em MACIEL 2006) e os óleos de junípero e cedro (II,IX.13 como citado em MACIEL 2006). O óleo de cedro é mencionado também por Plínio (XVI. 198 como citado em BosTOCK \& RILEY 1855).

Atendendo a que a madeira usada para escoramentos e entivações nos interiores das minas está por norma em contacto com águas, i.e., sujeita a um ambiente com elevado grau de humidade, terá de ser bastante resistente à detioração. $\mathrm{O}$ carvalho seria uma das madeiras mais adequadas para tal fim, já que é muito utilizado para fundações e construção naval (ULRICH 2007: 257).

As três madeiras atrás referidas também são boas para combustível, possuindo a madeira de azinho um alto poder calorífico, 20,6 x $10^{6} \mathrm{MJ} / \mathrm{kg}$ (CORDERO et al. 2001).

\section{CONSIDERAÇÕES FINAIS}

Carvalho, castanho, azinho, madeiras duras e resistentes, cujas propriedades são normalmente próprias para fundações / alicerces, construção naval e outros, teriam sido as madeiras privilegiadas na mineração romana, com ambientes por vezes de temperaturas contrastantes - agrestes, húmidos e com água, e secos.

A madeira é utilizada no processo de exploração mineira propriamente dita, servindo para escoramentos e travejamentos no interior de galerias e poços, para construção de estruturas de apoio e mecanismos de elevação de águas, para encabar instrumentos mineiros, e produzir outros. Posteriormente, no tratamento do minério a madeira seria necessária para construção de estruturas de lavagem e separação do minério, e como combustível dos fornos no processo metalúrgico (Fig. 8).

O objectivo do trabalho foi a identificação das funcionalidades de cada um dos artefactos em madeira estudados, atendendo às suas tipologias, no mundo romano e actuais, pois muitas sobrevivem ao longo dos tempos, assim como as técnicas construtivas. Tal facto dificulta a atribuição de cronologias, que no entanto se imputam ao período romano pela articulação com os demais materiais arqueológicos encontrados / exumados conjuntamente, assim como pela datação do local dos trabalhos de mineração, onde as peças foram encontradas.

Claro está que como material perecível que é, a madeira torna-se um elemento raro e precioso numa intervenção arqueológica, pois a sua preservação ao longo dos tempos em muito depende do ambiente em que a mesma se encontra. Daí que por vezes a

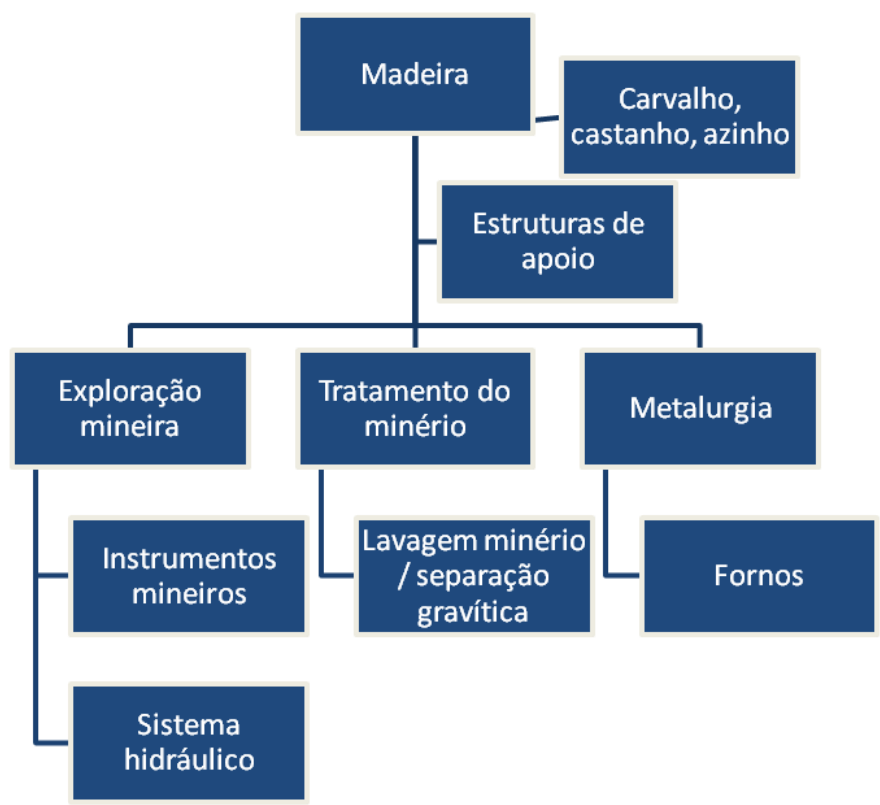

Fig. 8. Síntese da utilização da madeira em todo o processo de exploração mineira.

Fig. 8. Synthesis of the wood utilization in the whole process of mining exploration. 
historiografia e fontes orais acabam por ser complementares à arqueologia, preservando não somente os objectos, mas sim a memória dos mesmos.

\section{BIBLIOGRAFIA}

Alarcão, A. M., (coord.) 1997. Portugal Romano. A exploração dos recursos naturais. Lisboa, MNA.

AlarCÃo, J. de 1987. Portugal Romano. Lisboa, Editorial Verbo.

ALARCÃo, J. de 1988. Roman Portugal. England, Aris \& Phillips Ltd., vol. II

ALLAN, J. C. 1965. A mineração em Portugal na antiguidade. Boletim de Minas, 2(3): 139-175.

ANDRADE R. F. D’ 1970. A lavra romana das minas de Algares e na Herdade do Montinho. In Actas e Memórias do I Congresso Nacional de Arqueologia, Lisboa, Instituto de Alta Cultura: vol. II, 273-285.

Borges, P. C. B. 2013. Caracterização das propriedades fisicas e mecânicas da madeira de carvalho e de castanho do Nordeste Transmontano. Dissertação de Mestrado, Instituto Politécnico de Bragança.

Bostock, J. \& RiLey, H. T. 1855. The Natural History of Pliny. London, Henry G. Bohn: Volume III.

BRAGA, J. F. 1961. Relatório ácerca da mina de cobre, sita na serra de S. Domingos, freguezia de Sant'Anna de Cambas, concelho de Mértola, districto de Beja. Boletim do Ministério das Obras Públicas, Commercio e Industria, 11: 398-402.

CARneIro, A. M. 1998. Estabelecimentos mineiros romanos na bacia do Guadiana. Algares, 7: 155-121.

Cordero, T., Marquez, F., Rodrigyez-Mirasol, J., RODRIGUES, J. J. 2001. Predicting heating values of lignocellulosis and carbonaceous materials from proximate analysis. Fuel, 80:1567-1571.

Domergue, C. 1983. La mine antique d'Aljustrel (Portugal) et les tables de bronze de Algares. Conímbriga, 22: 5 -193 .

Domergue, C. 1987. Catalogue des mines et des fonderies antiques de la Péninsule Ibérique. Madrid, Diffusion de Boccard : vol. I.

Domergue, C. 2002. La mina romana de Aljustrel (Portugal) y el patrimonio minero a principios del tercer milenio. In BRANDÃo, J. M., Actas do Congresso Internacional sobre Património Geológico e mineiro, Lisboa, Instituto Geológico e Mineiro, 231-238.

FERNÁNDEZ JURADO, J. 1988-89. Aspectos de la mineria y la metalurgia en la protohistoria de Huelva. Huelva Arqueologica, 10-11(3): 178-214.

Hoover, H. C. \& Hoover, L. H. 1950. Georgius Agricola. De Re Metallica. New York, Dover Publications, Inc.

Humphries, C. J., Press, J. R. \& Sutton, D. A. 2005. Árvores de Portugal e Europa. Porto, FAPAS.

HuyseCom, E. \& Agustoni, B. 1996. INAGINA - L'ultime maison du fer. Genève, Huysecom, Agustoni e PAVE (audiovisual).

JÚNIOR, J. A. B. 2006. Avaliação não destrutiva da capacidade resistente de estruturas de madeira de edificios antigos. Dissertação de Mestrado, Faculdade de Engenharia da Universidade do Porto.
LOBO, L. S. \& TRIMM, D. L. 1977. Microstructure of deposits formed on iron by the catalytic decomposition of butane. Revista Portuguesa de Química, 19: 350354.

MACIEL, J. 2006. Vitrúvio. Tratado de arquitectura. Lisboa, IST Press.

MARTINS, C. M. B. 2008. A exploração mineira romana e a metalurgia do ouro em Portugal. Braga, Instituto de Ciências Socias da Universidade do Minho.

MARTINS, C. M. B. 2017 (prelo). Capítulo 4. Arqueometalurgia no territorium metallorum de Tresminas/Jales, Vila Pouca de Aguiar. In Martins, C. M. B., MACHADO, P., Martins, J. I. (coord.), Territorium Metallorum Tresminas/Jales, Vila Pouca de Aguiar. Vila Pouca de Aguiar: Câmara Municipal de Vila Pouca de Aguiar / AOURO.

Morais, I., Campos, J. S., Favas, P. J. C., Pratas, J., Pita, F. \& PRASAD, M. N. V. 2015. Nickel accumulation by Alyssum serpyllifolium subsp. Lusitanicum (Brassicaceae) from serpentine soils of Bragança and Morais (Portugal) ultramafic massifs: plant-soi relationships and prospects for phytomining. Australian Journal of Botany, 63, 17-30.

NogueirA, A. DE M. 1936. Uma exploração de minas de ouro da época romana. Revista de Arqueologia, 3: 201205.

Ramos, S. I. N. 2009. Caracterização das propriedades mecânicas e durabilidade biológica da madeira de quercus faginea. Dissertação de Mestrado, Instituto Superior de Agronomia da Universidade Técnica de Lisboa.

SÁnChEZ-Palencia, F. J. 2015. La zona minera de Tresminas (Vila Pouca de Aguiar. Aportaciones a partir de la fotografía aérea. Conímbriga, 54: 179-223.

UlRICH, R. B. 2007. Roman woodworking. New Haven e London, Yale University Press.

Viana, A., Andrade, R. F. DE \& Ferreira, O. DA V. 1954. Minerações romanas de Aljustrel. Comunicações dos Serviços Geológicos de Portugal, 35: 79-90.

WAHL, J. 1988. Três Minas. Madrider Mitteilungen, 29: 221244.

WAHL, J. 1993a. Minas romanas de Três Minas, Vila Pouca de Aguiar. Vila Pouca de Aguiar, Câmara Municipal de V. P. Aguiar.

WAHL, J. 1993b. Três Minas. Vorberich über die archäologischen Ausgrabungen im Bereich des römischen Goldbergwerks 1986/87. In Montanarchäologie in Europa, Freiburg, Jan Thorbecke Verlag Sigmaringen: 123-152.

WAHL, J. 1998. Aspectos tecnológicos da indústria mineira e metalúrgica romana de Três Minas e Campo de Jales (concelho de Vila Pouca de Aguiar). In Actas do Seminário Museologia e Arqueologia Mineiras, Lisboa, I.G.M.: 57-68.

WAHL-Clerici, R., Wiechowski, A., HelFert, M., RAMMINGER, B. \& SCHIERL, T. 2015. Die Mühlsteinproduktion im Steinbruch von Fonte da Ribeira. Zum römisch en Bergw erksdistrikt von Três Minas, Gralheira und Campo de Jales (distr. Vila Real / P). Archäologisches Korrespondenzblatt, 45: 379-393. 